\title{
Staphylococcus aureus supernatant induces the release of mouse $\beta$-defensin-14 from osteoblasts via the p38 MAPK and NF-kB pathways
}

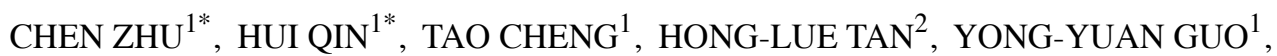 \\ SI-FENG SHI ${ }^{1}$, DE-SHENG CHEN ${ }^{1}$ and XIAN-LONG ZHANG ${ }^{1}$
}

\author{
${ }^{1}$ Department of Orthopaedic Surgery, Shanghai Sixth People's Hospital, Shanghai Jiao Tong University \\ School of Medicine, Shanghai 200233; ${ }^{2}$ Department of Orthopaedic Surgery, Shanghai Ninth People's Hospital, \\ Shanghai Jiao Tong University School of Medicine, Shanghai 200011, P.R. China
}

Received February 6, 2013; Accepted April 3, 2013

DOI: $10.3892 / \mathrm{ijmm} .2013 .1346$

\begin{abstract}
Mammalian $\beta$-defensins are small cationic peptides of approximately 2-6 kDa that have been implicated in mediating innate immune defenses against microbial infection. Previous studies have reported that mouse $\beta$-defensin-14 (MBD-14), based on structural and functional similarities, appears to be an ortholog of human $\beta$-defensin-3 (HBD-3). The aim of this study was to identify the signaling pathways that contribute to the expression of MBD-14 in mouse osteoblasts (OBs) upon contact with methicillin-resistant Staphylococcus aureus (S. aureus) supernatant (SAS) to provide a theoretical basis for the use of MDB-14 as a therapeutic agent in the treatment of intramedullary infection with $S$. aureus in vivo. The bacterial exoproducts released by $S$. aureus mainly include a large amount of enterotoxins. Using mouse OBs, the release and regulation of MBD-14 was evaluated by real-time polymerase chain reaction (PCR) and enzyme-linked immunosorbent assay (ELISA) following exposure to SAS. The activation of the p38 mitogen-activated protein kinase (MAPK), extracellular signal-regulated kinase (ERK) and nuclear factor- $\mathrm{\kappa B}(\mathrm{NF}-\mathrm{\kappa B})$ pathways was determined by western blot analysis. OBs treated with lipopolysaccharide (LPS) were used as the positive control. The results revealed that SAS significantly promoted the phosphorylation of p38 MAPK, NF- $\mathrm{kB}$ and the inhibitory subunit of NF- $\kappa \mathrm{B} \alpha(\mathrm{I} \kappa \mathrm{B} \alpha)$ in a time-dependent manner. The treatment of OBs with SB203580 (an inhibitor of p38 MAPK) and pyrrolidine dithiocarbamate (PDTC, an inhibitor of NF- $\mathrm{kB}$ ) prior to
\end{abstract}

Correspondence to: Dr Xian-Long Zhang, Department of Orthopaedic Surgery, Shanghai Sixth People's Hospital, Shanghai Jiao Tong University School of Medicine, 600 Yishan Road, Shanghai 200233, P.R. China

E-mail: zx140@vip.sina.com

*Contributed equally

Key words: Staphylococcus, signaling pathway, innate immunity, $\beta$-defensin, osteoblast stimulation with SAS significantly inhibited the phosphorylation and mRNA expression of $\mathrm{p} 38$ MAPK and NF- $\mathrm{kB}$ p65, simultaneously reducing the release of MBD-14. Our findings suggest that the release of MBD-14 is mediated at least in part through the activation of $\mathrm{p} 38 \mathrm{MAPK}$ and NF- $\mathrm{kB}$ in response to S. aureus-secreted bacterial exoproducts. Moreover, our data demonstrate the innate immune capacity of OBs under conditions of bacterial challenge to enhance the local expression of this MBD-14, a peptide with anti-staphylococcal activity.

\section{Introduction}

As an opportunistic human pathogen, Staphylococcus aureus (S.aureus) has become the main cause of nosocomial infections and is one of the major pathogens in osteomyelitis and implantrelated infections (1). Novel approaches to the management and further understanding of the pathophysiology of bone infection are urgently required. Evidence demonstrates that bacterially infected osteoblasts $(\mathrm{OBs})$ secrete chemokines, cytokines and antimicrobial peptides, suggesting that these cells may contribute to appropriate host responses or progressive inflammatory damage in combating localized infection (2-4). Clinical antimicrobial prophylaxis, including the systemic and local use of antibiotics, has proven to be valuable in the prevention of infection in clinical practice (5). However, the misuse of antibiotics has led to the evolution and rapid spread of clinical bacterial strains resistant to one or several conventional antimicrobial agents $(5,6)$. As a result, an increasing number of infections involving methicillin-resistant S. aureus (MRSA), even 'Superbugs', have emerged (1,7). Presently, the global spread of MRSA is a matter of great concern in the treatment of staphylococcal infection, since it has rapidly acquired resistance to all clinical antibacterial agents (8). In light of this situation, antimicrobial peptides are attractive candidates as therapeutic agents for bacterial infections due to their selectivity, speed of action, relative difficulty in the selection of resistant mutants, and inherent immunological compatibility (9).

A major family of antimicrobial proteins in mammals comprises the $\beta$-defensins. $\beta$-defensins are small (2-6 kDa), cationic proteins which exhibit potent antimicrobial activity 
at micro- to nanomolar concentrations (10). Previous studies have shown that $\beta$-defensins activate the innate immune system within bone and may potentially be used for reducing the rate of peri-implant infections (4). Human $\beta$-defensin (HBD)-3 is characterized by its strong, broad-spectrum, and salt-insensitive antibacterial activity against several bacteria, including multiresistant strains, such as MRSA and vancomycin-resistant Enterococcus faecium (11). Previously, we demonstrated the bactericidal effect of HBD-3 and its role in inhibiting the formation of MRSA (ATCC 43300) biofilms (12). In a recent study, murine homologs of HBDs, termed mouse $\beta$-defensins (MBDs) were isolated and characterized. To date, more than 10 different mouse $\beta$-defensins have been isolated (13). A BLAST search of the mouse protein database with the amino acid sequence of HBD-3 revealed great similarity to mouse $\beta$-defensin-14 (MBD-14). Futhermore, recombinant MBD-14, similar to HBD-3, has also exhibited similar broad-spectrum, nanomolar microbicidal activity against a variety of microorganisms, including Grampositive and -negative bacteria and the yeast, Candida albicans. These data suggest that MBD-14 is the structural and functional ortholog of HBD-3 $(14,15)$. Therefore, it may prove useful to investigate the expression and regulation of MBD-14 in vitro based on its homology to the human ortholog, HBD-3.

Several studies have reported that the expression of MBD-14 can be induced in epithelial tissue following mechanically- and metabolically-induced skin barrier disruption under inflammatory conditions (16). The p38 mitogen-activated protein kinases (p38 MAPK) and extracellular signal-regulated kinase (ERK) signaling pathways have been shown to regulate human $\beta$-defensin 2 mRNA expression in middle ear epithelial cells by inflammatory stimuli (17). These data suggest that pleural mesothelial cells contribute to host innate immune defense upon exposure to Gram-positive bacteria or their products within the pleural space, by increasing p38 MAPK activity and upregulating MBD-2 expression (18). In addition, Varoga et al demonstrated the effective induction of HBD-3 expression via Toll-like receptor (TLR)-2 and - 4 in OBs incubated with bacterial conditioned medium using enzyme-linked immunosorbent assay (ELISA) and real-time polymerase chain reaction (PCR) (19). However, the molecular mechanisms underlying inflammatory mediator-induced MBD-14 expresssion in OBs remain unknown. Furthermore, it is crucial to provide a theoretical basis for the use of MDB-14 as a therapeutic agent in the treatment of intramedullary infection with MRSA in vivo. Lipopolysaccharide (LPS), which is a major component of the outer surface of Gram-negative bacteria, stimulates murine OBs to induce pro-inflammatory cytokines, including interleukin-6 (IL-6) and tumor necrosis factor- $\alpha(\mathrm{TNF}-\alpha)$, through the activation of the nuclear factor- $\kappa \mathrm{B}$ $(\mathrm{NF}-\kappa \mathrm{B})$ pathway (20). Therefore, LPS is suitable as a positive control for inflammatory response to evaluate whether the model of acute inflammation and signaling pathways for OBs have been established. In this study, we confirmed the effects of MRSA supernatant (SAS) on the release of MBD-14 in mouse OBs, and targeted signaling pathways to elucidate the molecular mechanisms underlying the effects of inflammatory stimuli.

\section{Materials and methods}

Bacteria and drugs. ATCC 43300 (MRSA) was purchased in a freeze-dried form from the American Type Culture Collection
(ATCC; Rockefeller, MD, USA). Species identification and susceptibility testing was performed with the Vitek 2 automated system (Bio Mérieux, Marcy I'Étoile, France). The phenotypic classification of the ATCC 43300 strain was further confirmed by methicillin-resistant determinant A (MecA) expression, which encodes PBP2a (penicillin-binding protein $2 \mathrm{a}$ ) and mediates methicillin resistance (21). Recombinant MBD-14 was commercially available and purchased from EIAab Science Co., Ltd. (Wuhan, China). Pyrrolidine dithiocarbamate (PDTC), SB203580, antibodies against p-ERK, p-p38 MAPK, NF- $\kappa$ B p65, NF- $\kappa$ B p-P65, p-I $\kappa$ B $\alpha$ and GAPDH were purchased from Cell Signaling Technology Inc. (Danvers, MA, USA).

Cultivation of mouse OBs. The murine osteoblastic cell line, MC3T3-E1, is a non-transformed cell line established from newborn mouse calvaria. These cells exhibit the osteoblastic phenotype, as evidenced by the expression of ALPase (22), synthesis of the extracellular matrix (ECM) components, such as osteocalcin and type-1 collagen, and their ability to mineralize the ECM (22). MC3T3-E1 cells (ATCC, Manassas, VA, USA) were cultured in DMEM (Gibco, Grand Island, NY, USA), supplemented with $10 \%$ heat-inactivated fetal bovine serum, $2 \mathrm{mM}$ glutamine, $100 \mathrm{U} / \mathrm{ml}$ penicillin and $100 \mu \mathrm{g} / \mathrm{ml}$ streptomycin, in a humidified atmosphere of $5 \% \mathrm{CO}_{2}$ in air at $37^{\circ} \mathrm{C}$. Cells were trypsinized and cultivated for an additional 2 days before use at an appropriate density. When the monolayers reached approximately $85 \%$ confluence, stimulation experiments were performed in serum-free DMEM containing ascorbic acid in a humidified atmosphere with $5 \% \mathrm{CO}_{2}$ at $37^{\circ} \mathrm{C}$ as previously described (23).

Stimulants. The production of bacterial culture supernatants was carried out as previously described by Gläser et al (24). In this method, ATCC 43300 bacteria were grown in BBL Trypticase Soy Broth (TSB; BD Biosciences, Franklin Lakes, NJ, USA) under shaking conditions at $37^{\circ} \mathrm{C}$ until they reached an optical density of $1.0 ; 1 \mathrm{ml}$ of this culture was then added to $9 \mathrm{ml}$ TSB and the resulting culture was incubated for $24 \mathrm{~h}$ in $50-\mathrm{ml}$ centrifuge tubes (Corning Inc., NY, USA) without shaking. Subsequently, the bacteria were centrifuged at 5,000 x $\mathrm{g}$ for $15 \mathrm{~min}$ and then cell-free conditioned medium was prepared by filtering the supernatant through a $0.22-\mu \mathrm{m}$ pore-size filter (Tullagreen, Carrigtwohill, County Cork, Ireland) (25). The resulting supernatants were used for stimulation experiments. Stimulation experiments with TSB medium were performed to analyze the potentially unexpected effects of the medium. The concentration of SAS was determined by the number of $S$. aureus bacteria in the resulting culture incubated for $24 \mathrm{~h}$ as previously described (19). The number of colony-forming units (CFUs) was counted and expressed relative to the amount of TSB for planktonic bacteria in $50 \mathrm{ml}$ centrifuge tubes (CFUs/ $\mathrm{ml})$. Mouse OBs in the monolayer culture were exposed to various concentrations of SAS (diluted 1:10, 1:20, 1:40 and $1: 80$, i.e., the number of OBs vs. the concentration of bacterial exoproducts from the number of Staphylococcus aureus).

Cell viability assay. A Cell Counting kit-8 (Beyotime, Shanghai, China) was used to examine cell viability according to the manufacturer's instructions. MC3T3-E1 cells were seeded at $1 \times 10^{4}$ cells/well in 96-well culture plates (Corning Inc.) and 
Table I. Nucleotide sequences for the primers used in this study.

\begin{tabular}{|c|c|c|c|c|}
\hline Target gene & Direction & Primer sequence $\left(5^{\prime}-3^{\prime}\right)$ & Annealing temperature $\left({ }^{\circ} \mathrm{C}\right)$ & Size (bp) \\
\hline p38 MAPK & $\begin{array}{l}\mathrm{F} \\
\mathrm{R}\end{array}$ & $\begin{array}{l}\text { CGTGTGGCAGTTAAGAAGC } \\
\text { GGCACTTCACGATGTTGTT }\end{array}$ & 57 & 214 \\
\hline ERK & $\begin{array}{l}\mathrm{F} \\
\mathrm{R}\end{array}$ & $\begin{array}{l}\text { TGCTGAACACCACTTGTGA } \\
\text { GGAAGATAGGCCTGTTGGA }\end{array}$ & 57 & 219 \\
\hline $\mathrm{I} \kappa \mathrm{B} \alpha$ & $\begin{array}{l}\mathrm{F} \\
\mathrm{R}\end{array}$ & $\begin{array}{l}\text { GCAATCATCCACGAAGAGA } \\
\text { ATCACAGCCAGCTTTCAGA }\end{array}$ & 57.5 & 168 \\
\hline NF-кB p65 & $\begin{array}{l}\mathrm{F} \\
\mathrm{R}\end{array}$ & $\begin{array}{l}\text { CCCACCATCAAGATCAATG } \\
\text { TATGGATACTGCGGTCTGG }\end{array}$ & 56.5 & 160 \\
\hline$\beta$-actin & $\begin{array}{l}\mathrm{F} \\
\mathrm{R}\end{array}$ & $\begin{array}{l}\text { AATGGGTCAGAAGGACTCCT } \\
\text { ACGGTTGGCCTTAGGGTTCAG }\end{array}$ & 56 & 250 \\
\hline
\end{tabular}

F, forward; R, reverse; MAPK, mitogen-activated protein kinase; ERK, extracellular signal-regulated kinase; IкB $\alpha$, inhibitory subunit of $\mathrm{NF}-\kappa \mathrm{B} \alpha ; \mathrm{NF}-\kappa \mathrm{B}$, nuclear factor- $\kappa \mathrm{B}$.

were then treated with SAS at various concentrations at $37^{\circ} \mathrm{C}$ in a humidified incubator containing $95 \%$ air and $5 \% \mathrm{CO}_{2}$. After $12,24,48$ and $72 \mathrm{~h}$, the $10 \mu \mathrm{l} \mathrm{CCK}-8$ solution was added to each well and incubated for $1 \mathrm{~h}$ in an incubator. The absorbance was measured using a Synergy HT multidetection microplate reader (BioTek Instruments, Inc., Winooski, VT, USA) at a wavelength of $450 \mathrm{~nm}$ as previously described $(26,27)$.

Real-time PCR. At various time points, the cells treated with SAS at various concentrations were harvested and total RNA was isolated using an RNeasy Mini kit (Qiagen, Valencia, CA, USA) according to the manufacturer's instructions with an additional DNase I (Fermentas)-treatment step to eliminate residual genomic DNA. Total RNA $(1 \mu \mathrm{g})$ was reverse transcribed using a Fermentas RevertAid First Strand cDNA Synthesis kit (Thermo Fisher Scientific, Inc., Waltham, MA, USA). Real-time PCR was performed on an ABI 7500 Fast machine (Applied Biosystems, Courtaboeuf, France) using Roche FastStart Universal SYBR-Green Master (Rox) (Roche Applied Science, Indianapolis, IN, USA). The reactions were performed using cDNA templates and specific forward and reverse primers (Table I). Refer to Table I for the detailed annealing temperature which was used according to the different primers. The specificity of the amplification reaction was determined by analyzing the melting curves. The relative amount of target gene expression was normalized to $\beta$-actin as an internal control. The quantification of gene expression was based on the cycle threshold value of each sample, which was calculated as the average of 3 replicate measurements for each sample analyzed as previously described $(12,28)$.

ELISA. The collected supernatants from the different stimulation experiments were examined by MBD-14, DEFb14 ELISA kit (EIAab Science Co., Ltd.) according to the manufacturer's instructions. ELISA was performed on each sample in triplicate. The optical density of each sample was measured with a Synergy HT multidetection microplate reader (BioTek Instruments) at a wavelength of $450 \mathrm{~nm}$. The examination of TNF- $\alpha$ and IL- 6 levels was performed according to the standard protocols of the ELISA kit (EIAab Science Co., Ltd.).
Western blot analysis. Cells in a 6-well plate were harvested under different conditions and washed with PBS 3 times. Protein was extracted using the Total protein Extraction kit according to the manufacturer's instructions (ProMab Biotechnologies, Inc., Richmond, CA, USA). Proteins were quantified using the BCA protein assay kit (Pierce Biotechnology, Inc., Rockford, IL, USA). Samples containing equal amounts of protein $(40 \mu \mathrm{g} /$ lane) were run on $12 \%$ polyacrylamide gels, transferred onto nitrocellulose membranes (Whatman, Dassel, Germany) and blocked for $1 \mathrm{~h}$ with $5 \%$ non-fat milk in TBST (Tris-buffered solution containing $0.1 \%$ Tween-20) at room temperature. The membranes were then soaked with primary antibodies overnight at $4^{\circ} \mathrm{C}$ followed by secondary antibody incubation for $1 \mathrm{~h}$ at room temperature. Finally, the membranes were reacted with enhanced chemiluminescence (ECL) reagents and band densities were determined using Gel Pro 4.0 analyzer software (Media Cybernetics Inc., Bethesda, MD, USA) and the integrated optical density (IOD) was calculated as previously described (29).

Statistical analysis. The results are expressed as the means \pm SEM derived from at least 3 independent experiments. Statistical analysis between groups was performed by one-way ANOVA. The level of $\mathrm{p}<0.05$ was considered to indicate a statistically significant difference. SPSS software (version 19.0; IBM, Chicago, IL, USA) was used for statistical analysis.

\section{Results}

Phenotype classification, minimum inhibitory concentration (MIC) and bacterial count. ATCC 43300 exhibited a low level of susceptibility to penicillin (MIC, $64 \mu \mathrm{g} / \mathrm{ml}$ ) and recombinant MBD-14 exhibited a strong antimicrobial activity against ATCC 43300 (MIC, $8 \mu \mathrm{g} / \mathrm{ml}$ ). According to a low level susceptibility to penicillin and MecA gene expression, ATCC 43300 was the methicillin-resistant strain (21). In addition, the amount of bacteria in the resulting culture was calculated as approximately $3.5 \pm 0.6 \times 10^{9} \mathrm{CFUs} / \mathrm{ml}$ using the spread plate method. 

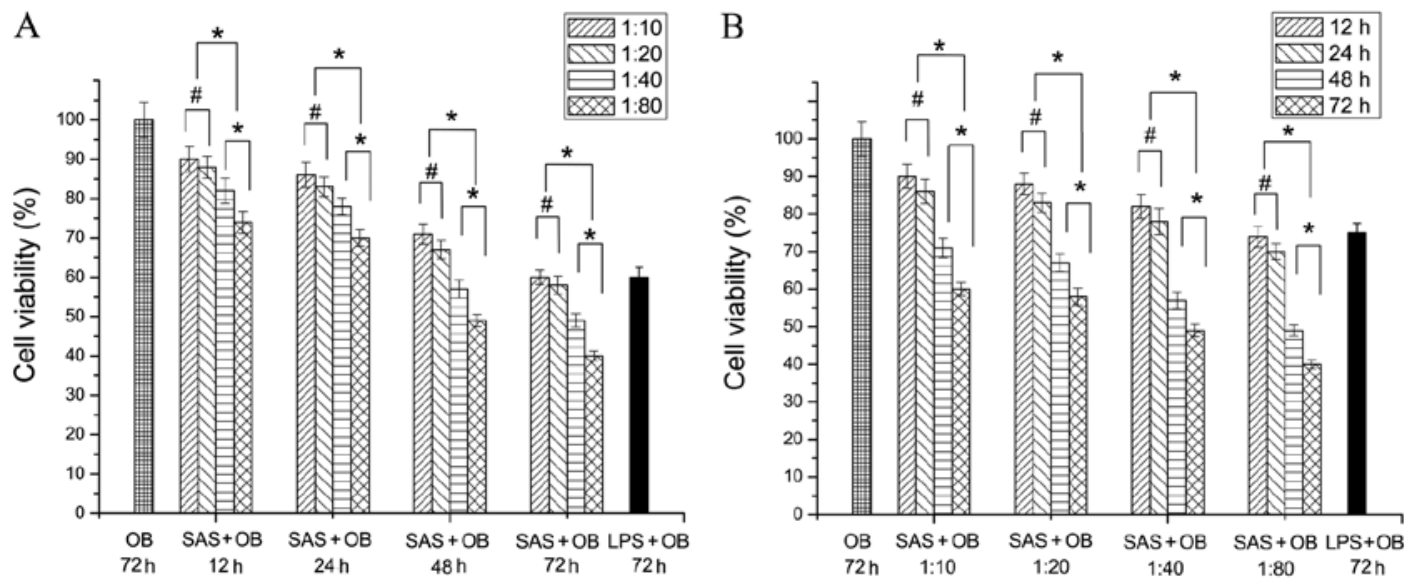

Figure 1. Treatment with various concentrations of Staphylococcus aureus supernatant (SAS) inhibit the proliferation of osteoblasts (OBs). (A) Cells were cultured with various concentrations of SAS for the same periods of time. (B) Cells were cultured with the same concentration of SAS for different periods of time. Data are the means \pm SD. ${ }^{*}$ Statistically significant differences between the 2 groups, $p<0.05$; ${ }^{*}$ no significant difference, $p>0.05$.

SAS inhibits the proliferation of primary mouse OBs. In order to determine the optimal proportion and action time of the mixed agent which could contribute to the inflammatory reaction with low cytotoxic response, a cytotoxicity assay was conducted to investigate the effects of culture with various concentrations of SAS on OBs at different time points (12, 24, 48 and $72 \mathrm{~h})$. We first evaluated the effect of various concentrations of SAS on cell viability. OBs were treated with SAS for $12,24,48$ and $72 \mathrm{~h}$, at the following concentrations: diluted at 1:10, 1:20, 1:40 and 1:80. Throughout the incubation period, cell proliferation was analyzed using a CCK-8 kit. At $72 \mathrm{~h}$, treatment with $10 \mu \mathrm{g} / \mathrm{ml}$ LPS was used as the positive control to evaluate whether the cell proliferation was already affected. All investigated treatment ratios from 1:20 to 1:80 induced less $\mathrm{OB}$ proliferation compared to the untreated group (OB group), as shown in Fig. 1 ( $p<0.05)$. In the OB group in which OBs without SAS stimulation were cultured for $72 \mathrm{~h}$, the proliferation of cells measured by CCK-8 assay was highest and normalized to $100 \%$ (negative control). At $12 \mathrm{~h}$, the proliferation of cells was the highest at the 1:10 treatment ratio, followed by the 1:20 treatment ratio. However, no significant difference was observed ( $p>0.05)$. A lower cell number was consistently observed in the groups treated with higher concentrations than those treated with the concentration of 1:10 and 1:20 $(\mathrm{p}<0.05)$. Moreover, the lowest cell numbers were observed in the group treated with the concentration of 1:80 $(\mathrm{p}<0.05)$, and the same findings were observed at 24, 48 and $72 \mathrm{~h}$ (Fig. 1A). When the cells were cultured with the same concentrations of bacterium-free supernatant for different periods of time, the levels of cell proliferation positively correlated with the duration (Fig. 1B). The proliferation of cells was the highest at $12 \mathrm{~h}$, followed by $24 \mathrm{~h}$. However, no significant difference was observed $(\mathrm{p}>0.05)$. Furthermore, the lowest number of OBs was observed in the group treated for $72 \mathrm{~h}$, followed by the group treated for $48 \mathrm{~h}$. The difference between these 2 groups was significant. The above findings regarding the different treatment times were observed at different concentrations (Fig. 1B).

Release of the pro-inflammatory cytokines, TNF- $\alpha$ and IL-6, in infected OBs. Subsequently, the level of the pro-inflamma- tory cytokines, TNF- $\alpha$ and IL-6, was assessed by ELISA at different time points $(12,24,48$ and $72 \mathrm{~h})$ when the cells were incubated with various concentrations of SAS. At $72 \mathrm{~h}$, treatment with $10 \mu \mathrm{g} / \mathrm{ml}$ LPS was used as the positive control to evaluate whether the model of acute inflammation for OBs has been established. When the cells were cultured with different doses of bacterium-free supernatant, the levels of TNF- $\alpha$ and IL-6 positively correlated with the concentrations of bacteriumfree supernatant and the duration. The levels of TNF- $\alpha$ in the SAS + OB and LPS + OB groups treated with different concentrations for different periods of time were significantly higher than those of the OB group at $72 \mathrm{~h}$ (negative control). As shown in Fig. 2A, the release of TNF- $\alpha$ with SAS stimulation was the lowest at the concentration of 1:10 at $12 \mathrm{~h}$, followed by the 1:20, 1:40 and 1:80 concentrations. Moreover, a significant difference was observed between the 1:10 and 1:20 concentrations, and the highest level of inflammatory cytokines was observed at the concentration of 1:80. At 24, 48 and $72 \mathrm{~h}$, the levels of TNF- $\alpha$ showed a similar tendency to those of TNF- $\alpha$ at $12 \mathrm{~h}$ (Fig. 2A). Obviously, at the concentration of 1:20, there was statistically significant difference in the level of inflammatory cytokines between 12 and $24 \mathrm{~h}$. In addition, no statistically significant differences were observed between the group treated with the concentration of 1:20 at $24 \mathrm{~h}$ and the LPS + OB group (positive control) (Fig. 2B). The SAS + OB group treated at the concentration of 1:20, which increased the level of TNF- $\alpha$ at $24 \mathrm{~h}$ showed similar abilities compared with the LPS + OB group, suggesting an effective stimulation of the OBs. The variation trend of IL- 6 showed a similarity with that of TNF- $\alpha$ (Fig. 2C and D). In conclusion, the results of CCK-8 assay and ELISA for TNF- $\alpha$ and IL- 6 showed that the optimal ratio of the mixed agent was 1:20 and the optimal treatment time was $24 \mathrm{~h}$.

$M B D-14$ release is continuously induced in SAS-challenged $O B s$. To confirm the constitutive expression of MBD-14 and determine whether mouse OBs are a suitable model to examine the induction of MBD-14 following exposure to bacterial supernatant and LPS, the protein level of secreted MBD-14 in cell culture supernatants was examined by ELISA. Cells stimulated with SAS (1:20) were incubated for 12, 24 and 

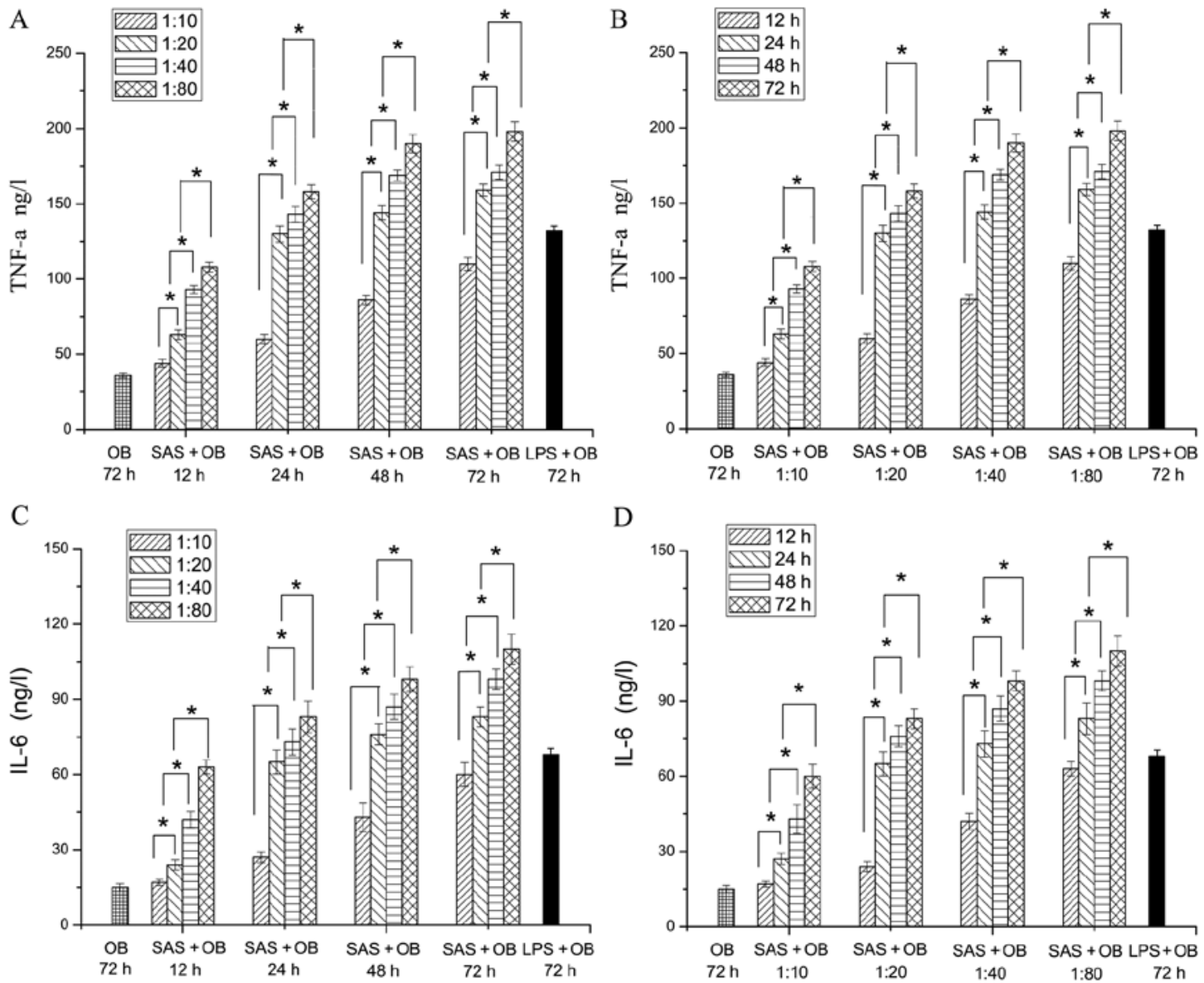

Figure 2. Treatment with various concentrations of Staphylococcus aureus supernatant (SAS) stimulate the release of (A and B) TNF- $\alpha$ and (C and D) IL-6 at different time points examined by enzyme-linked immunosorbent assay (ELISA) in mouse osteoblasts (OBs). (A and C) Cells were cultured with various concentrations of SAS for the same periods of time. (B and D) Cells were cultured with the same concentration of SAS for different periods of time. Data are the means \pm SD. "Statistically significant differences between the 2 groups, $\mathrm{p}<0.05$.

A

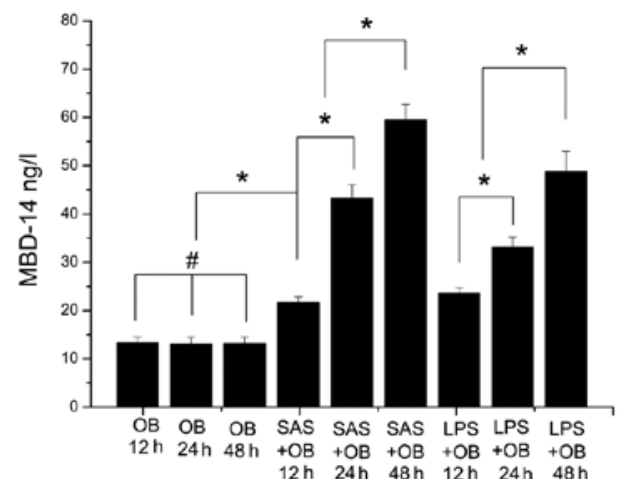

B

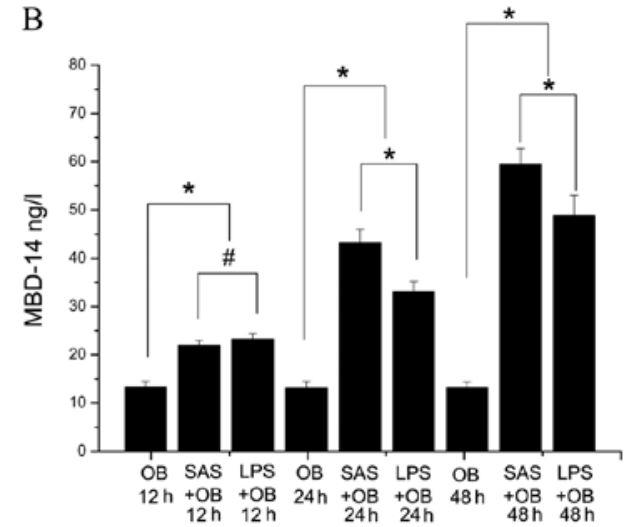

Figure 3. Induction of mouse $\beta$-defensin-14 (MBD-14) in primary mouse osteoblasts (OBs). Enzyme-linked immunosorbent assay (ELISA) experiments were performed to assess the amount of MBD-14 released after 12, 24 and $48 \mathrm{~h}$ of exposure to Staphylococcus aureus supernatant (SAS) or lipopolysaccharide (LPS) .(A) Same treatment conditions for different periods of time. (B) Different treatment conditions for the same periods of time. Data are the means \pm SD. "Statistically significant differences between the 2 groups; " ${ }^{*}$ o significant difference, $\mathrm{p}>0.05$.

$48 \mathrm{~h}$ and SAS significantly increased the release of MBD-14 compared to the untreated controls (OB group) (Fig. 3A) $(\mathrm{p}<0.05)$. The level of MBD-14 at $12 \mathrm{~h}$ was the lowest at all time points following stimulation. In addition, bacterial stimulation increased the level of MBD-14 by up to 3-fold, similar to the OB group after $24 \mathrm{~h}(\mathrm{p}<0.05)$. The SAS-induced MBD-14 secretion level peaked within $48 \mathrm{~h}$ (approximately $60 \mathrm{ng} / \mathrm{ml}$ ) (Fig. 3A) $(\mathrm{p}<0.05)$. Fig. 3B demonstrates the higher level of MBD-14 induction following stimulation with SAS compared to treatment with LPS at 24 and $48 \mathrm{~h}(\mathrm{p}<0.05)$. This upregulation was more pronounced when SAS was used appropriately as a stimulus. 


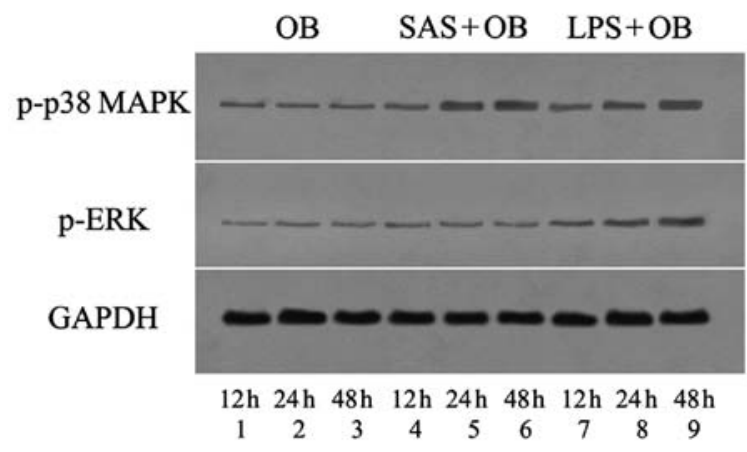

Figure 4. Western blot analysis assays verified the effects of Staphylococcus aureus supernatant (SAS) on p38 mitogen-activated protein kinase (MAPK) and extracellular signal-regulated kinase (ERK) activation under different treatment conditions. Osteoblasts (OBs) were treated without (lanes 1-3) or with SAS (1:20, lanes 4-6) or lipopolysaccharide (LPS) (lanes 7-9) for the indicated periods of time. Pre-incubation with specific antibody revealed only a weak detection in the OB group (lane 1,12 h; lane 2, $24 \mathrm{~h}$; and lane 3,48 h). Lane 4, cells stimulated with SAS for $12 \mathrm{~h}$; lane 5, cells stimulated with SAS for $24 \mathrm{~h}$; and lane 6, cells stimulated with SAS for $48 \mathrm{~h}$. Lane 7, cells incubated with LPS for $12 \mathrm{~h}$; lane 8, cells incubated with LPS for $24 \mathrm{~h}$; and lane 9, cells incubated with LPS for $48 \mathrm{~h}$.

Role of $p 38$ MAPK in the SAS-induced release of MBD-14. The p38 and other intracellular MAPK pathways have been implicated in the regulation of HBD-3 expression, in a number of bacterial stimulation models in primary keratinocytes (25). To examine the overall level of p38 and ERK activation (phosphorylation) in OBs challenged with $S$. aureus secreted bacterial exoproducts, the cells lysed at various time points following exposure to SAS were used for the detection of the phosphorylated form of p38 and ERK by immunoblot analysis (Figs. 4 and 5A and B). Real-time PCR was used to demonstrate the mRNA expression of p38 MAPK and ERK upon stimulation with SAS (Fig. 5C and D). Furthermore, the amount of MBD-14 released from OBs exposed to bacterial supernatants was then examined by ELISA (Fig. 9D). As shown in Figs. 4 and 5, cells without SAS stimulation contained a discernible level of activated p38 MAPK at the baseline. However, the mRNA expression and the phosphorylation of p38 MAPK gradually increased within $12 \mathrm{~h}$ and remained elevated for at least $48 \mathrm{~h}$ with SAS (1:20) and $10 \mu \mathrm{g} /$ $\mathrm{ml}$ LPS stimulation, a striking contrast to that of ERK at 3 time points (Figs. 4 and 5). Moreover, the treatment of OBs with LPS increased p38 MAPK and ERK activation within $12 \mathrm{~h}$, and this level of activation persisted for at least $48 \mathrm{~h}$. Subsequently, the contribution of p38 MAPK activation to the SAS-induced release of MBD-14 was investigated using the selective inhibitor, SB203580, which specifically inhibits the phosphorylation of the downstream kinases of $\mathrm{p} 38$ isoforms $\alpha$ and $\beta$. Pre-treatment of the cells with SB203580 for 30 min prior to exposure to SAS significantly inhibited the SAS-induced phosphorylation and mRNA expression of p38 MAPK, and significantly attenuated

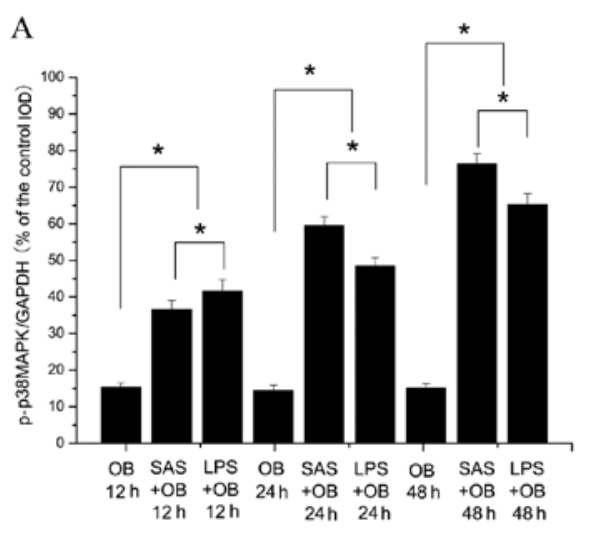

B
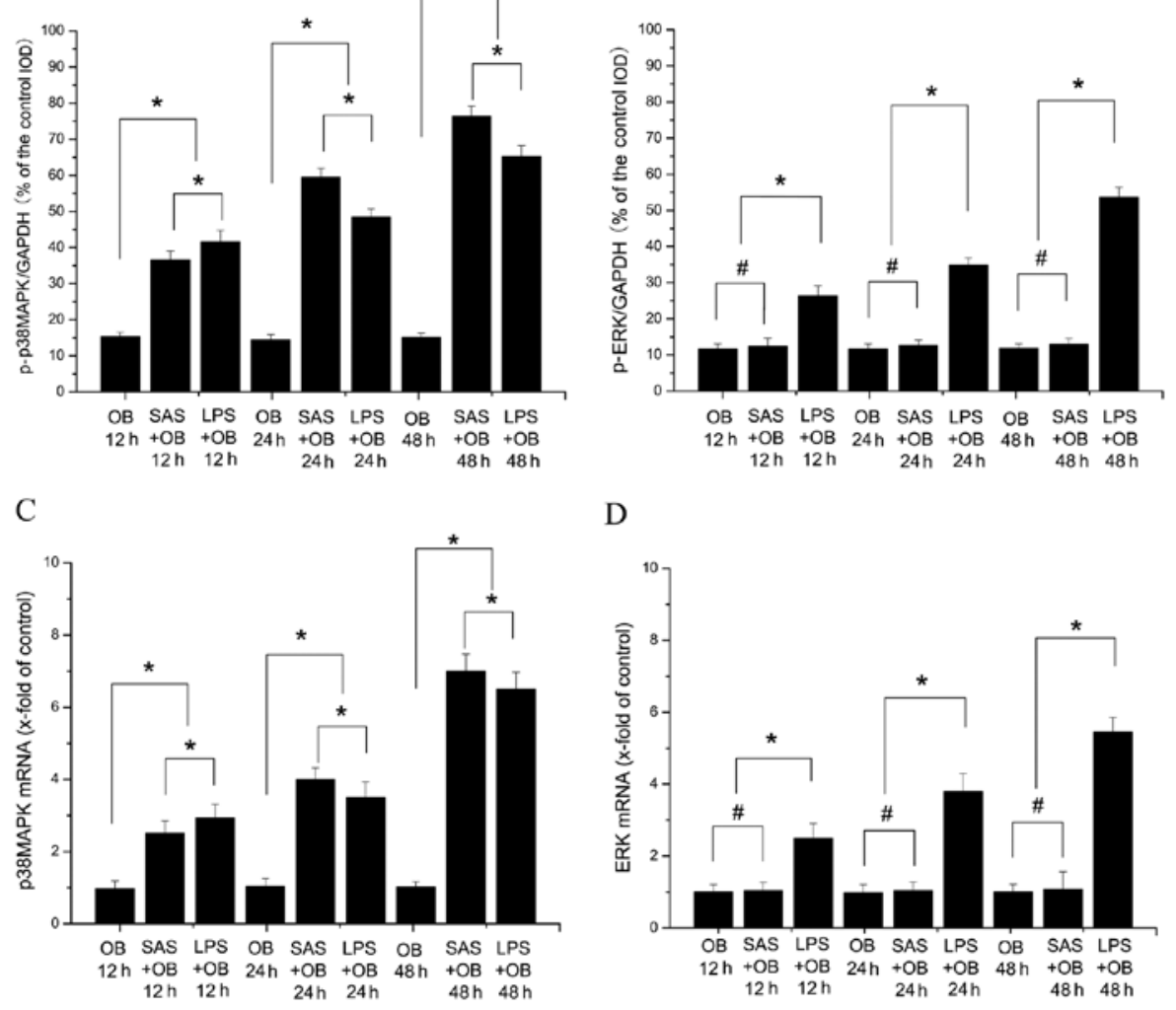

D

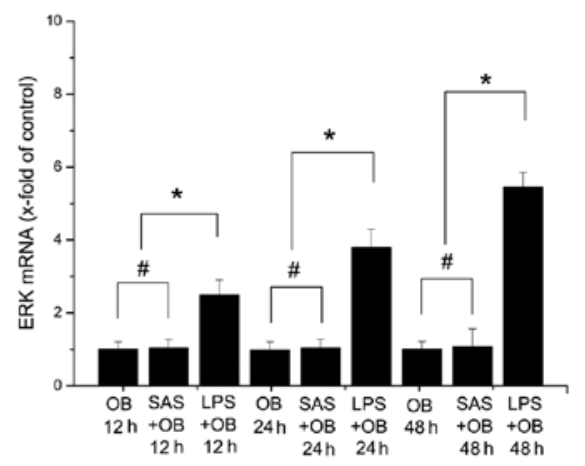

Figure 5. Quantitative integrated optical density (IOD) analysis of p-p38 mitogen-activated protein kinase (MAPK) and p-ERK protein levels by western blot analysis. (A and B) The densities of phosphorylated protein levels were normalized to those of the GAPDH group. (C and D) Real-time PCR analyzed the expression levels of p38 MAPK and extracellular signal-regulated kinase (ERK) mRNA. Cells were treated with Staphylococcus aureus supernatant (SAS) (the SAS + OB group) for the indicated periods of time compared with the osteoblast (OB) (negative control) and lipopolysaccharide (LPS) + OB group (positive control). The expression levels of p38 MAPK and ERK mRNA normalized to the internal standard gene $\beta$-actin. The mRNA levels shown are the relative mRNA levels compared to the mRNA levels in the control group. Data are the means \pm SD. "Statistically significant differences between the 2 groups; " no significant difference, $\mathrm{p}>0.05$. 


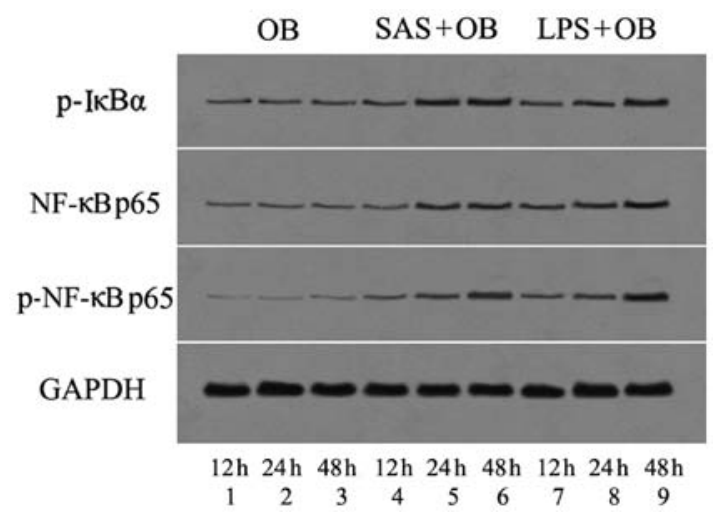

Figure 6. Western blot analysis assays verified the effects of Staphylococcus aureus supernatant (SAS) on nuclear factor- $\mathrm{KB}(\mathrm{NF}-\mathrm{\kappa B})$ activation under different treatment conditions. As described in the Fig. 4, cells were treated without or with Staphylococcus aureus supernatant (SAS) or lipopolysaccharide (LPS). At each time point, whole cell lysates were prepared for $\mathrm{p}-\mathrm{I} \kappa \mathrm{B} \alpha$ NF-kB p65 and p-NF- $\mathrm{kB}$ p65. The integrated optical density (IOD) values of the blots were calculated analysis using analyzer software. Signal transduction pathways of NF-kB were activated after 12, 24 and $48 \mathrm{~h}$ following SAS stimulation (lanes 4-6). Lanes 1-3, OB group; lanes 4-6, SAS + OB group; lanes 7-9, LPS + OB group.

the release of MBD-14 (Figs. 8 and 9A, D and E). After using SB203580, the amount of MBD-14 released decreased to almost $20 \mathrm{ng} / \mathrm{ml}$ at $24 \mathrm{~h}$ and $30 \mathrm{ng} / \mathrm{ml}$ at $48 \mathrm{~h}$, which was significantly lower than the levels in the the OB + SAS group $(\mathrm{p}<0.05)$
(Fig. 9D). These results suggest that the p38 MAPK signaling pathway is involved in the SAS-induced release of MBD-14, whereas ERK is not.

Role of $N F-\kappa B$ in the SAS-induced release of $M B D-14 . \mathrm{NF}-\kappa \mathrm{B}$ has been shown to be involved in the transcriptional activation of pro-inflammatory cytokines, including IL-6 and TNF- $\alpha$, in murine OBs exposed to extracellular stimuli (20). To determine whether bacterial exoproducts affect the activity of the NF- $\kappa \mathrm{B}$ pathway in OBs, the cells lysed at various time points following exposure to SAS were used for the detection of the phosphorylated form of the inhibitory subunit of $\mathrm{NF}-\kappa \mathrm{B} \alpha(\mathrm{I} \kappa \mathrm{B} \alpha)$ and $\mathrm{NF}-\kappa \mathrm{B}$ by western blot analysis (Figs. 6 and 7A-C). We examined whether SAS increased the mRNA expression of NF- $\kappa$ B p65 by real-time PCR (Fig. 7D). Within $12 \mathrm{~h}$ following treatment with SAS (1:20) and $10 \mu \mathrm{g} / \mathrm{ml}$ LPS, the mRNA expression of NF- $\kappa \mathrm{B}$ p 65 and the phosphorylation of $\mathrm{I} \kappa \mathrm{B} \alpha$ and $\mathrm{NF}-\kappa \mathrm{B}$ p65 slightly increased to the basal level. At later time points, the SAS-induced phosphorylation and mRNA expression of $\mathrm{NF}-\kappa \mathrm{B}$ p 65 and $\mathrm{I} \kappa \mathrm{B} \alpha$ increased within $24 \mathrm{~h}$ and reached a maximal level at $48 \mathrm{~h}$. Moreover, treatment of the cells with LPS increased $\mathrm{NF}-\kappa \mathrm{B}$ activation within $12 \mathrm{~h}$, and this level of activation persisted for at least $48 \mathrm{~h}$ (Figs. 6 and 7A-C). Subsequently, we examined the role of the NF- $\mathrm{B}$ signaling pathway in the SAS-induced MBD-14 expression. The downregulation of the $\mathrm{NF}-\kappa \mathrm{B}$ pathway by the relative inhibitor, PDTC, was verified by western blot analysis and real-time PCR (Figs. 8 and 9F). The cells were pre-treated for $30 \mathrm{~min}$ with $20 \mu \mathrm{M}$ PDTC and then
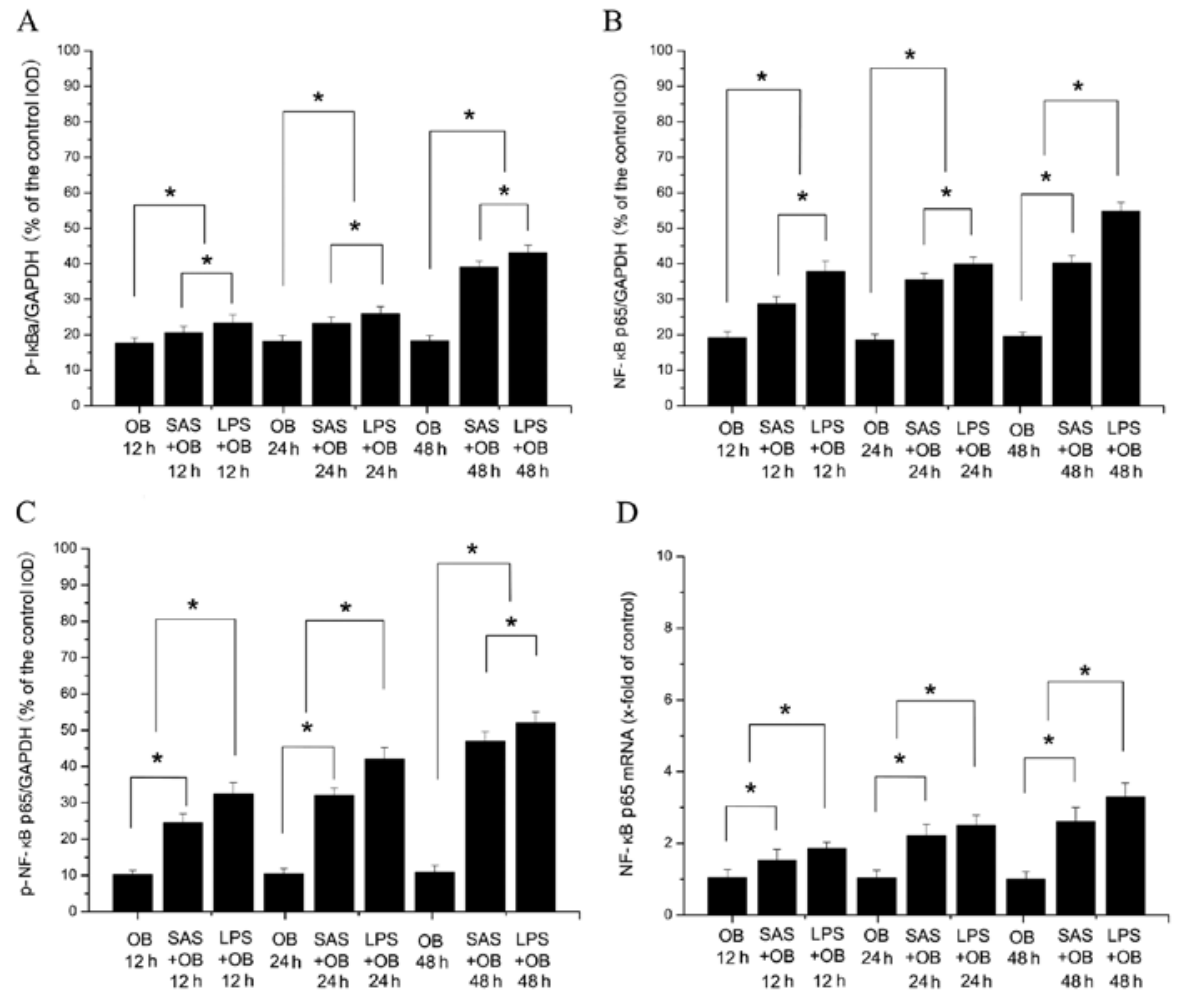

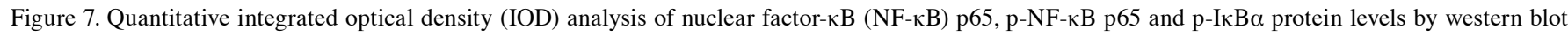
analysis. (A-C) The densities of protein levels were normalized to those of the GAPDH group. (D) Real-time PCR analyzed the expression level of NF- $\mathrm{kB}$ p65 mRNA. As described in the Fig. 5C and D, cells were treated with Staphylococcus aureus supernatant (SAS) for the indicated periods of time compared with the osteoblast (OB) and lipopolysaccharide (LPS) + OB group. The expression level of NF- $\mathrm{kB}$ p65 mRNA normalized to the internal standard gene, $\beta$-actin. The mRNA level shown is the relative mRNA level compared to the mRNA level in the control group. Data are the means \pm SD. "Statistically significant differences between the 2 groups. 


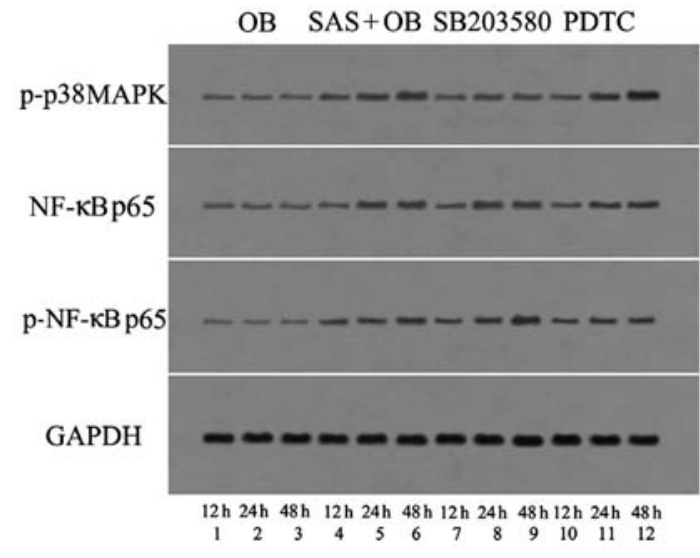

Figure 8. Western blot analysis assays demonstrated whether the crosstalk existed between $\mathrm{p} 38$ mitogen-activated protein kinase (MAPK) and nuclear

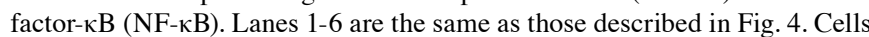
were pre-treated with pyrrolidine dithiocarbamate (PDTC) $(20 \mu \mathrm{M}$, lanes 7-9) or SB203580 (20 $\mu \mathrm{M}$; lanes 10-12) for an additional $30 \mathrm{~min}$ and then treated with Staphylococcus aureus supernatant (SAS) for the indicated periods fo time. At each time point, whole cell lysates were used for p-p38 MAPK,

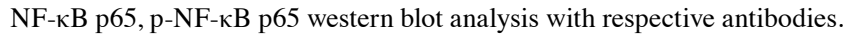

treated with SAS for an additional 12, 24 and $48 \mathrm{~h}$, followed by the measurement of the phosphorylation and mRNA expression of NF-kB p65. Pre-treatment of cells with PDTC markedly inhibited the SAS-induced phosphorylation of NF- $\mathrm{BB}$ p 65 at the different time points (Figs. 8 and 9B and C). Correspondingly, the amount of MBD-14 released decreased to $24 \pm 2.1 \mathrm{ng} / \mathrm{ml}$ at $24 \mathrm{~h}$ and $34 \pm 2.8 \mathrm{ng} / \mathrm{ml}$ at $48 \mathrm{~h}$ following pre-treatment with PDTC, which was far lower than the level in the OB + SAS group $(\mathrm{p}<0.05)$ (Fig. 9D). These results suggest that $\mathrm{NF}-\kappa \mathrm{B}$ mediates the SAS-induced MBD-14 expression.

Crosstalk between different signaling pathways. To determine whether the SAS-induced activation of the p38 MAPK pathway is mediated through $\mathrm{NF}-\kappa \mathrm{B}$, the cells were pre-treated for 30 min with the inhibitor, PDTC, and then treated with SAS for an additional 12, 24 and $48 \mathrm{~h}$, followed by the measurement of the phosphorylation and mRNA expression of p38 MAPK. PDTC did not significantly alter the phosphorylation and mRNA expression of $\mathrm{p} 38$ MAPK in response to SAS treatment $(p<0.05)$ (Figs. 8 and 9E). These results suggest that the NF- $\mathrm{B}$ pathway does not regulate p38 MAPK activation. In order to determine whether the SAS-induced activation of $N F-\kappa B$ is mediated through the p38 MAPK pathway, the cells were pretreated for 30 min with SB203580 and then treated with SAS for different periods of time, followed by the measurement of the phosphorylation and mRNA expression of NF- $\kappa \mathrm{B}$ p65. Subsequently, SB203580 did not inhibit the activation of $\mathrm{NF}-\kappa \mathrm{B}$ p65 in response to SAS treatment (Figs. 8 and 9F). These results suggest that the p38 MAPK pathway does not regulate $\mathrm{NF}-\kappa \mathrm{B}$ activation.

\section{Discussion}

In this study, we demonstrate that SAS significantly induces the release of MBD-14, a peptide with potent anti-staphylococcal activity, in the murine osteoblastic cell line, MC3T3-E1. To our knowledge, this is the first study demonstrating that the molec- ular mechanisms leading to the enhanced release of MBD-14 from OBs may partly involve the activation of the p38 MAPK and NF- $\kappa \mathrm{B}$ pathways in response to $S$. aureus secreted bacterial exoproducts. Previous studies have focused on the primary roles of OBs in synthesizing the components of the bone matrix and regulating the activity of bone resorption (23). However, increasing evidence indicates that they have additional tasks in bone infection. A previous study provided evidence that OBs play an important role in controlling bacterial bone infection through the constitutive secretion of $\beta$-defensins, verified in tissue samples of cultured OBs and infected mandibular bone (4). The constitutive expression of MBD-14 in samples of cultured OBs in our study was in accordance with previous findings. Furthermore, previous studies have suggested the effective induction of HBD-3 stimulated with SAS in OBs; however, the molecular mechanisms underlying the SAS-induced $\beta$-defensin release from OBs remain unknown (19).

In this study, the role of the p38 MAPK and NF- $\mathrm{B}$ pathways in the release of the structural and functional ortholog of HBD-3, MBD-14 following SAS stimulation was evaluated. The p38 MAPK pathway is an important regulator of several cellular processes. This key intracellular signal transduction pathway controls fundamental cellular activities, such as cell growth, cell proliferation, differentiation and migration, as well as apoptosis. In addition, it modulates the expression of antimicrobial peptides, such as HBD-2 in epithelial cells and HBD-3 in keratinocytes during inflammation $(25,30)$. In our cell culture model, p38 MAPK, as opposed to ERK, was significantly phosphorylated in the SAS-treated OBs. We provide evidence that the p38 MAPK pathway participates in the SAS-induced release of MBD-14. SB203580, a well-characterized chemical inhibitor of p38, attenuated the phosphorylation and the mRNA expression of p38 MAPK, as well as the release of MBD-14 by $\mathrm{SAS}$. The transcription factor, $\mathrm{NF}-\mathrm{\kappa B}$, is composed of homoor heterodimers of NF- $\mathrm{BB}$ family members, Rel-A/p65, Rel-B, c-Rel, p50 and p52. In the canonical NF- $\kappa$ B pathway, SAS activates the I $\kappa \mathrm{B}$ kinase, which in turn phosphorylates NF- $\mathrm{BB}$ associated $\mathrm{I} \kappa \mathrm{B}$, leading to the ubiquitination and degradation of $\mathrm{I} \kappa \mathrm{B}$. The NF- $\mathrm{B}$ dimers, p50 and p65, are sequentially released and translocated into the nucleus to regulate gene transcription. Moreover, it is well known that RelA/p65 is a critical transactivation subunit for NF- $\mathrm{BB}$ (31). Our results revealed that SAS (diluted 1:20) significantly induced the phosphorylation of $\mathrm{I} \kappa \mathrm{B} \alpha$ and the degradation of $\mathrm{I} \kappa \mathrm{B} \alpha$, which ultimately led to the phosphorylation of $\mathrm{NF}-\kappa \mathrm{B}$ p 65 and in turn increased the transactivation activity of NF- $\kappa \mathrm{B}$. Pre-treatment with PDTC markedly inhibited the SAS-induced phosphorylation and mRNA expression of NF- $\kappa \mathrm{B}$ p65 at different time points (30). The amount of MBD-14 released from the OBs pre-treated with PDTC markedly decreased compared with that in the $\mathrm{OB}+\mathrm{SAS}$ group. The reduced secretion of MBD-14 following treatment with inhibitors indicates the role of these pathways in sensing Gram-positive microbes and mediating anti-inflammatory response in cultured OBs. Further studies are required to elucidate the p38 MAPK and NF- $\kappa$ B binding motifs of the MBD-14 gene promoter which contribute to the SAS-mediated transcription, as well as the other signaling pathways responsible for MBD-14 expression in OBs (32).

The main cause of bacterial bone infection is due to S. aureus colonization (1). We therefore assessed the influ- 

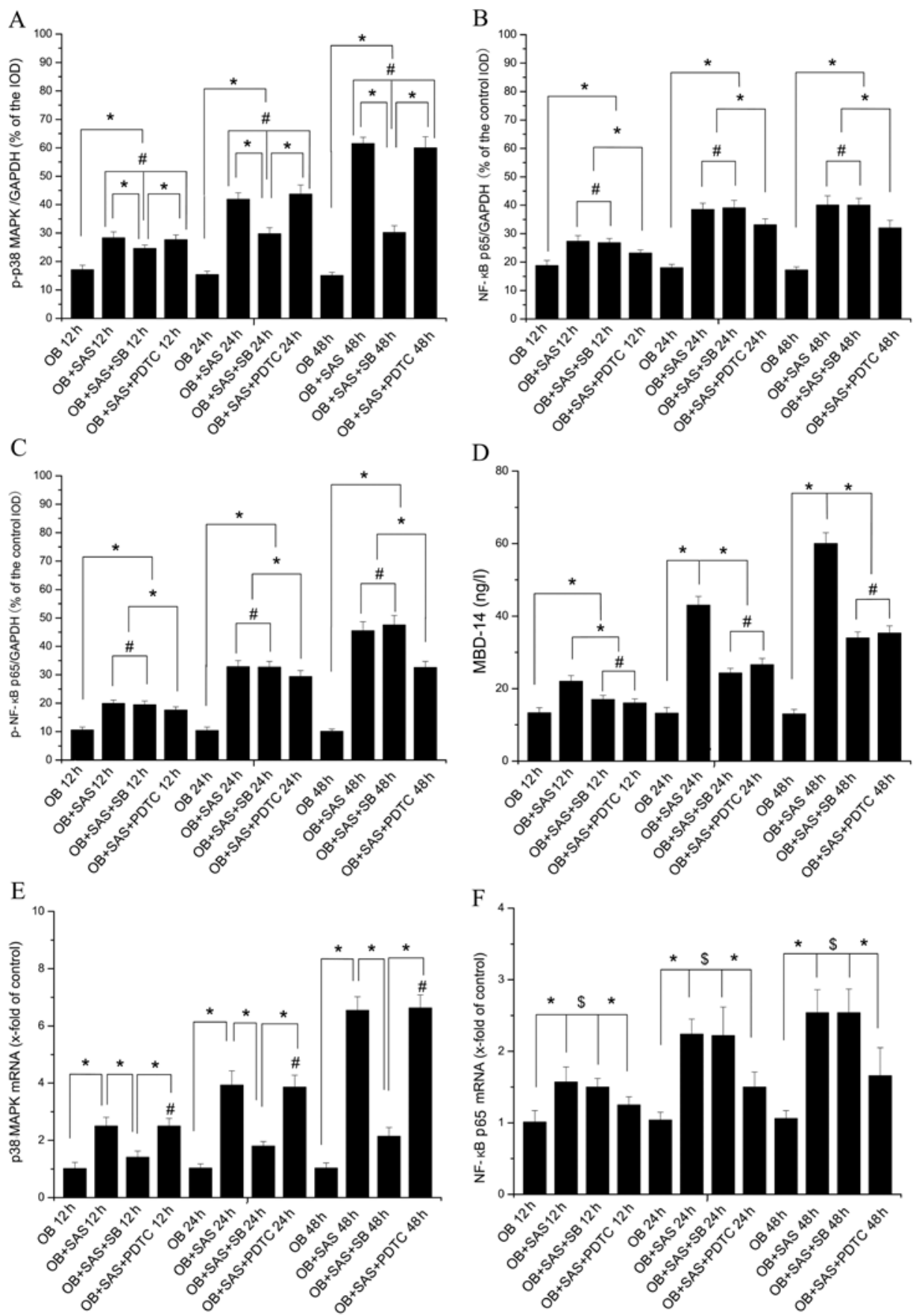

Figure 9. (A-C) Quantitative integrated optical density (IOD) analysis of p-p38 mitogen-activated protein kinase (MAPK), nuclear factor- $\mathrm{B}$ (NF- $\mathrm{\kappa}$ ) p65 and p-NF-кB p65 protein levels by western blot analysis. (D) The densities of protein levels were normalized to those of the GAPDH group. Cells supernatant were assayed for enzyme-linked immunosorbent assay (ELISA). Cells were pre-treated with pyrrolidine dithiocarbamate (PDTC) (20 $\mu \mathrm{M})$ or SB203580 (20 $\mu \mathrm{M})$ and then treated with Staphylococcus aureus supernatant (SAS). The amount of mouse $\beta$-defensin-14 (MBD-14) released from the osteoblast (OB) + SAS + SB and OB + SAS + PDTC groups was compared with that released from the OB and OB + SAS group. (E and F) Real-time PCR analyzed the expression levels of p38 MAPK and NF-kB p65 mRNA. As described in the Fig. 5C and D, cells were pre-treated with SB203580 (SB) or PDTC and then treated with SAS. The expression levels of $\mathrm{p} 38$ MAPK and NF- $\mathrm{kB}$ p 65 mRNA were normalized to the internal standard gene, $\beta$-actin. The mRNA levels shown are the relative mRNA levels compared to the mRNA levels in the control group. Data are the means \pm SD. "Statistically significant differences between the 2 groups; the OB + SAS group vs. the $\mathrm{OB}+\mathrm{SAS}+\mathrm{PDTC}$ group at the same time points, 12,24 and $48 \mathrm{~h} ;\left(\mathrm{E},{ }^{\sharp \$} \mathrm{p}>0.05\right) ;{ }^{\mathrm{s \sharp}}$ no statistically significant differences between the 2 groups.

ence of S. aureus supernatants on the release of MBD-14 from cultured OBs. The bacterial exoproducts released by S. aureus mainly included a large amount of toxins, such as enterotoxins that act at very low concentrations and have superantigenic activity to trigger a complex molecular pathway, ultimately leading to an increased expression of pro-inflammatory genes $(33,34)$. Following the co-culture of OBs with SAS (1:20),
MBD-14 secretion increased to higher levels after $24 \mathrm{~h}$ and finally peaked after $48 \mathrm{~h}$. The marked upregulation of MBD-14 following exposure to Gram-positive bacterial exoproducts in this study, suggests an important role of antimicrobial peptides in host response in inflammatory bone disease. In addition, Lucke et al speculated whether the induction of HBD-3 in cultured hosteoblasts and bone play a dual role during immune 
response (35). Their direct antimicrobial properties contribute to the local innate immune response by combating microbial invasions. By linking innate and adaptive immune responses, $\beta$-defensins secreted by OBs may promote the production of pro-inflammatory mediators, chemoattract macrophages and monocytes, initiate the antigen-specific activation of infiltrating cells, and facilitate the development of cell-mediated host responses to invading pathogens (36-38). However, further studies are required to clarify the role of MBD-14 in immune defense, and to achieve a balance between their direct antimicrobial properties and the recruitment capabilities contributing to the innate and adaptive immune response.

Our data revealed an emerging framework for understanding the SAS-induced release of MBD-14 from OBs as part of host immunity. Of note, SAS and LPS significantly increased the release of MBD-14. Based on our data, we propose a novel method that $\mathrm{OBs}$ treated with relative agonists to activate p38 MAPK and $\mathrm{NF}-\kappa \mathrm{B}$ can effectively improve the release of MBD-14, protecting against microbial invasion during the early period of bone infection.

In conclusion, the findings of the present study demonstrate that SAS induces the release of MBD-14 in MC3T3-E1 cells which appears to be mediated at least in part through the activation of the signaling molecules, $\mathrm{p} 38 \mathrm{MAPK}$ and NF- $\mathrm{KB}$, but not ERK. The regulation of the expression of MBD-14 by different pathogens may be important in maintaining or augmenting the endogenous antimicrobial barrier in bone in response to bacterial invasion. The elucidation of the host signaling pathways that contribute to the induction of MBD-14 expression may aid in the understanding of host susceptibility to staphylococcal infection during various disease states, such as osteomyelitis and implant-related infection, and may provide novel therapeutic agents for enhancing innate defense mechanims within the bone. Further studies are required to investigate the effectiveness of the treatment of $S$. aureus intramedullary infection in vivo through a certain therapeutic agent. Our data may provide a new direction for research into this topic.

\section{Acknowledgements}

This study was supported by the Interdisciplinary (Engineering-Medical) Research Fund of Shanghai Jiao Tong University (Grant no. YG2011MS30), the Shanghai Municipal Health Bureau Science Fund for Young Scholars (Grant no. 2010QJ036A), the Opening Project of State Key Laboratory of High Performance Ceramics and Superfine Microstructure (Grant no. SKL201206SIC) and the National Natural Science Foundation of China (Grant no. 81171688).

\section{References}

1. Montanaro L, Speziale P, Campoccia D, et al: Scenery of Staphylococcus implant infections in orthopedics. Future Microbiol 6: 1329-1349, 2011.

2. Marriott I, Gray DL, Rati DM, et al: Osteoblasts produce monocyte chemoattractant protein-1 in a murine model of Staphylococcus aureus osteomyelitis and infected human bone tissue. Bone 37: 504-512, 2005.

3. Ning R, Zhang X, Guo X and Li Q: Staphylococcus aureus regulates secretion of interleukin- 6 and monocyte chemoattractant protein-1 through activation of nuclear factor kappaB signaling pathway in human osteoblasts. Braz J Infect Dis 15: 189-194, 2011
4. Warnke PH, Springer IN, Russo PA, et al: Innate immunity in human bone. Bone 38: 400-408, 2006.

5. Campoccia D, Montanaro L, Speziale P and Arciola CR: Antibiotic-loaded biomaterials and the risks for the spread of antibiotic resistance following their prophylactic and therapeutic clinical use. Biomaterials 31: 6363-6377, 2010.

6. Shi Z, Neoh KG, Kang ET, Poh C and Wang W: Titanium with surface-grafted dextran and immobilized bone morphogenetic protein-2 for inhibition of bacterial adhesion and enhancement of osteoblast functions. Tissue Eng Part A 15: 417-426, 2009.

7. Kumarasamy KK, Toleman MA, Walsh TR, et al: Emergence of a new antibiotic resistance mechanism in India, Pakistan, and the UK: a molecular, biological, and epidemiological study. Lancet Infect Dis 10: 597-602, 2010.

8. Zuo GY, An J, Han J, et al: Isojacareubin from the Chinese Herb Hypericum japonicum: potent antibacterial and synergistic effects on clinical methicillin-resistant Staphylococcus aureus (MRSA). Int J Mol Sci 13: 8210-8218, 2012.

9. Hancock RE: Mechanism of action of newer antibiotics for grampositive pathogens. Lancet Infect Dis 5: 209-218, 2005.

10. Pazgier M, Hoover DM, Yang D, Lu W and Lubkowski J: Human beta-defensins. Cell Mol Life Sci 63: 1294-1313, 2006.

11. Maisetta G, Batoni G, Esin S, Florio W, Bottai D, Favilli F and Campa M: In vitro bactericidal activity of human beta-defensin 3 against multidrug-resistant nosocomial strains. Antimicrob Agents Chemother 50: 806-809, 2006.

12. Zhu C, Tan H, Cheng T, et al: Human $\beta$-defensin 3 inhibits antibiotic-resistant Staphylococcus biofilm formation. J Surg Res: Dec 20, 2012 (Epub ahead of print).

13. Yamaguchi Y, Nagase T, Makita R, et al: Identification of multiple novel epididymis-specific beta-defensin isoforms in humans and mice. J Immunol 169: 2516-2523, 2002.

14. Hinrichsen K, Podschun R, Schubert S, Schröder JM, Harder J and Proksch E: Mouse beta-defensin-14, an antimicrobial ortholog of human beta-defensin-3. Antimicrob Agents Chemother 52: 1876-1879, 2008

15. Röhrl J, Yang D, Oppenheim JJ and Hehlgans T: Identification and biological characterization of mouse beta-defensin 14, the orthologue of human beta-defensin 3. J Biol Chem 283: 5414-5419, 2008.

16. Ahrens K, Schunck M, Podda GF, et al: Mechanical and metabolic injury to the skin barrier leads to increased expression of murine $\beta$-defensin-1, -3, and -14. J Invest Dermatol 131: 443-452, 2011.

17. Lee HY, Takeshita T, Shimada J, et al: Induction of beta defensin 2 by NTHi requires TLR2 mediated MyD88 and IRAK-TRAF6-p38 MAPK signaling pathway in human middle ear epithelial cells. BMC Infect Dis 8: 87, 2008.

18. Hussain T, Nasreen N, Lai Y, Bellew BF, Antony VB and Mohammed KA: Innate immune responses in murine pleural mesothelial cells: toll-like receptor-2 dependent induction of beta-defensin-2 by staphylococcal peptidoglycan. Am J Physiol Lung Cell Mol Physiol 295: L461-L470, 2008.

19. Varoga D, Wruck CJ, Tohidnezhad M, et al: Osteoblasts participate in the innate immunity of the bone by producing human beta defensin-3. Histochem Cell Biol 131: 207-218, 2009.

20. Die L, Yan P, Jun Jiang Z, Min Hua T, Cai W and Xing L: Glycogen synthase kinase-3 beta inhibitor suppresses Porphyromonas gingivalis lipopolysaccharide-induced CD40 expression by inhibiting nuclear factor-kappa B activation in mouse osteoblasts. Mol Immunol 52: 38-49, 2012.

21. Nihonyanagi S, Kanoh Y, Okada K, et al: Clinical usefulness of multiplex PCR lateral flow in MRSA detection: a novel, rapid genetic testing method. Inflammation 35: 927- 934, 2012.

22. Suzuki A, Guicheux J, Palmer G, et al: Evidence for a role of p38 MAP kinase in expression of alkaline phosphatase during osteoblastic cell differentiation. Bone 30: 91-98, 2002.

23. Han SH, Kim KH, Han JS, et al: Response of osteoblast-like cells cultured on zirconia to bone morphogenetic protein- 2 . J Periodontal Implant Sci 41: 227-233, 2011.

24. Gläser R, Harder J, Lange H, Bartels J, Christophers E and Schröder JM: Antimicrobial psoriasin (S100A7) protects human skin from E. coli infection. Nat Immunol 6: 57-64, 2005.

25. Menzies BE and Kenoyer A: Signal transduction and nuclear responses in Staphylococcus aureus-induced expression of human beta-defensin 3 in skin keratinocytes. Infect Immun 74: 6847-6854, 2006.

26. An N, Rausch-fan X, Wieland M, Matejka M, Andrukhov O and Schedle A: Initial attachment, subsequent cell proliferation/viability and gene expression of epithelial cells related to attachment and wound healing in response to different titanium surfaces. Dent Mater 28: 1207-1214, 2012. 
27. Li JY, Huang JY, Li M, et al: Anisomycin induces glioma cell death via down-regulation of PP2A catalytic subunit in vitro. Acta Pharmacol Sin 33: 935-940, 2012.

28. Tan H, Peng Z, Li Q, Xu X, Guo S and Tang T: The use of quaternised chitosan-loaded PMMA to inhibit biofilm formation and downregulate the virulence-associated gene expression of antibiotic-resistant Staphylococcus. Biomaterials 33: 365-377, 2012.

29. Bar-Yehuda S, Luger D, Ochaion A, et al: Inhibition of experimental auto-immune uveitis by the A3 adenosine receptor agonist CF101. Int J Mol Med 28: 727-31, 2011.

30. Jang BC, Lim KJ, Paik JH, et al: Up-regulation of human beta-defensin 2 by interleukin-1 beta in A549 cells: involvement of PI3K, PKC, p38 MAPK, JNK, and NF-kappaB. Biochem Biophys Res Commun 320: 1026-1033, 2004

31. Shim KS, Kang JS, Lee MH and Ma JY: Selaginella tamariscina water extract inhibits receptor activator for the nuclear factor- $\kappa \mathrm{B}$ ligand-induced osteoclast differentiation by blocking mitogen-activated protein kinase and NF- $\kappa \mathrm{B}$ signaling. Pharmacogn Mag 8: 184-191, 2012.

32. Mineshiba J, Myokai F, Mineshiba F, Matsuura K, Nishimura F and Takashiba S: Transcriptional regulation of beta-defensin-2 by lipopolysaccharide in cultured human cervical carcinoma (HeLa) cells. FEMS Immunol Med Microbiol 45: 37-44, 2005.
33. Hu DL, Omoe K, Sashinami H, Shinagawa K and Nakane A: Immunization with a nontoxic mutant of staphylococcal enterotoxin A, SEAD227A, protects against enterotoxin-induced emesis in house musk shrews. J Infect Dis 199: 302-310, 2009.

34. Rasooly R and Hernlem B: TNF as biomarker for rapid quantification of active Staphylococcus enterotoxin A in food. Sensors (Basel) 12: 5978-5985, 2012.

35. Lucke M, Schmidmaier G, Sadoni S, et al: Gentamicin coating of metallic implants reduces implant-related osteomyelitis in rats. Bone 32: 521-531, 2003.

36. Semple F, MacPherson H, Webb S, et al: Human $\beta$-defensin 3 affects the activity of pro-inflammatory pathways associated with MyD88 and TRIF. Eur J Immunol 41: 3291-3300, 2011.

37. Lai Y and Gallo RL: AMPed up immunity: how antimicrobial peptides have multiple roles in immune defense. Trends Immunol 30: 131-141, 2009.

38. Röhrl J, Yang D, Oppenheim JJ and Hehlgans T: Human beta-defensin 2 and 3 and their mouse orthologs induce chemotaxis through interaction with CCR2. J Immunol 184: 6688-6694, 2010. 